\title{
Painful disorders of peripheral nerves
}

\author{
C. B. WYNN PARRY \\ M.B.E., M.A., D.M., F.R.C.P., F.R.C.S. \\ R. H. WITHRINGTON \\ M.R.C.P.

\begin{abstract}
Department of Rheumatology and Rehabilitation Medicine, Royal National Orthopaedic Hospital, London and Stanmore
\end{abstract}

\section{Introduction}

The classical description of painful sequelae to peripheral nerve injury is that by Weir-Mitchell in his book Injuries of Nerves and their Consequences. This was published in 1872 and related to experience gained during the American Civil War.

Later, in 1900, Sudeck described an acute atrophy of bone, associated with swelling, pain and loss of function. A variety of terms are applied to this condition including reflex sympathetic dystrophy, Sudeck's atrophy and algodystrophy. Over the years many authors have pointed out the remarkable similarity clinically between painful sequelae of peripheral nerve damage, now known as causalgia and Sudeck's atrophy in that both are associated with severe spontaneous pain, swelling of the affected hand or foot, changes in the muscles, joints and skin and marked hypersensitivity over the innervated zone-later spreading to adjacent zones. Until recently it was believed that Sudeck's atrophy was a manifestation of an abnormal response of the sympathetic nervous system to injury, but recent work has shown that the sympathetic nervous system is not at fault but that it is a hypersensitivity of the large diameter afferent nerves to normal circulating noradrenaline that seems to be responsible (Wallin, Torebjörk and Hallin, 1976). Characteristically Sudeck's atrophy follows fairly trivial injuries, whereas causalgia is associated with partial division of peripheral nerves.

\section{Description of causalgia}

The picture of causalgia is one of severe burning pain in the hand or foot, often coming on immediately after injury and persisting for months or years. The pain occurs first in the distribution of the affected nerve and, after months or years, spreads to the territory of adjacent nerves. The skin is hyperaesthetic, and hyperpathia (allodynia) is usually present-defined as an abnormal response to normal stimuli such that the slightest touch causes severe pain. Sensory loss is usually slight but it is difficult to test, as the patient often refuses to allow the examiner to approach him. The small joints of the fingers may swell, there are characteristic changes in the nails, loss of hair, and at a late stage some patients may show involuntary movements. Later the joints swell and may become stiff and ankylosed, and give the appearance of rheumatoid arthritis.

The most famous case described by Weir-Mitchell is reproduced verbatim:

Jose H. Corliss, late Private of B Company, 14th New York, State Militia, aged 27, a shingle dresser enlisted April 1861. At the second battle of Bull Ram, August 29th 1862, he was shot in the left arm 3 inches above the internal condyle and the bullet emerged one and a quarter inches higher. He was ramming a cartridge when hit and thought he was struck on the crazy bone by some of the boys for a joke. Resection of the median nerve was no good. A week after he was shot in the right arm, he was weak and could not feed himself. By April 1864, he was better, he had pain in the median distribution but excessive pain in the ulnar. He kept his hand wrapped in a rag, wetted with cold water and covered in oil silk. Moisture was more essential to him than cold, he keeps a bottle of water about him, with a wet sponge in his right hand and keeps water in his boots. It is"as if a rough bar of iron was thrust to and fro through the knuckles and a red hot iron placed at the junction of the palm and thenar eminence with a heavy weight on it and the skin rasped off his finger ends. The rattling of a newspaper, a breath of air, the step of another across the ward, the vibrations caused by a military band, or the shock of the feet in walking gave rise to increase of pain. He insisted an observer 
wet his hand before touching him-cold weather eased it, heat made it worse.'

(Reproduced by permission of the publishers)

White, Heroy and Goodman (1948) state that in a few cases the burning pain undoubtedly subsides with time spontaneously or after surgical repair of the injured nerve, but the interval is so long that irreparable changes in the skin, muscles, bone and psyche may follow. Weir-Mitchell himself pointed out that in 50 partial nerve lesions there were several changes in the skin and bones in 19. In 1895, WeirMitchell's son (Mitchell, 1895) followed up 22 of his father's patients. He noted that 16 of the 22 were still having considerable problems with their pain-all five of the brachial plexus lesions, three of the six median and ulnar nerve lesions, two of the four sciatic lesions, two of the three median lesions, and both the unlar nerve lesions. This is therefore a serious condition with a poor prognosis, one that can cause lasting changes in the bones, joints, muscles and skin and with pain which may spread well beyond the autonomous zone of nerve damage.

Some $5 \%$ of partial nerve lesions are associated with causalgia. Why it develops in some patients but not in the vast majority is unknown. In rats, however, one strain is particularly prone to develop autotomy (self-mutilation) after deafferentation. This suggests that a genetic factor may be involved (Inbal et al., 1980).

It is often stated in the literature that patients develop Sudeck's atrophy because of a nervous temperament.

\section{Description of Sudeck's atrophy}

Three stages are generally recognised in this condition. In the first stage there is pain, hyperaesthesiae, hyperpathia, oedema, tenderness of the soft tissues and the hand or foot is warm, red and dry. In the second stage, joint changes appear, loss of hair is noticeable and the nails become brittle, curved and osteoporosis can be seen on X-rays. In the third stage marked trophic changes are seen, with glossy, smooth, cyanotic and pale skin with increase of temperature, marked nail changes, wasting of muscles, even ankylosis of joints with skin eruptions and palmar nodules. The close similarity with the changes described in causalgia is apparent. Livingston (1943) suggested that this condition resulted from damage to the smaller nerves in contradistinction to causalgia, and might follow simple Colles fractures and sprains. Loh and Nathan (1978) argue that causalgia and Sudeck's atrophy are at either end of a spectrum. The response to sympathetic block and the existence of hyperpathia are common to both. The immediate reaction to the injury, whether it be a strain or sprain producing a Sudeck's atrophy or a bullet producing causalgia, happens far too soon in a significant proportion of patients to offer other than an organic explanation. Moreover, once the pain has been relieved the patients rapidly resume a normal disposition.

\section{Recent developments}

In recent years there has been an explosion of interest in the phenomena that follow peripheral nerve damage (Wall and Sweet, 1967). Damage to a peripheral nerve results in the formation of a neuroma. This is a perfectly normal response to injury. However, in a small proportion of patients such neuromas become painful. Wall and Gutnik (1974) showed that the neuroma is the seat of spontaneous discharges. More recently they have shown that discharges appear in the posterior root ganglion within a week of injury. Furthermore, sprouts that grow from the distal end of the nerve may course back along the nerve for long distances and themselves be the site of spontaneous discharges. It is now well recognised that there is 'cross-talk' between demyelinated or abnormally myelinated fibres and that these may be the seat of spontaneous ectopic discharges. Ochoa and Torebjork (1981) have shown how normal peripheral nerves can becom8 ectopic generators along the whole length of the nerve, following ischaemia for as short a time as $2 \mathrm{E}$. min. They applied a sphygmomanometer cuff t $\bar{t}^{*}$ normal volunteers on the upper arm, kept it above systolic pressure for $20 \mathrm{~min}$ and then released it. They asked the subjects to describe their symptoms. At the same time, microelectrode recordings were made in the median and ulnar nerves at the wrist and elbow, so that the discharges recorded on the screen could be correlated with what was described by the subject. In one key experiment they showed that, despite blocking the ulnar nerve at the elbow, it was still possible to record high frequency discharges in the ulnar nerve at the wrist. The whole nerve had become an ectopic generator.

It is not difficult to see how an ulnar nerve damaged at the elbow can become the spontaneous generator of abnormal impulses leading to chronic pain. It is even more understandable how pain can be compounded by continued operations to re-route the nerve in a less vulnerable place. Each procedure can lead to further nerve damage and thus further abnormal firing. It is also now well recognised that the fibre sprouts in neuromas are highly sensitive to circulating noradrenaline. Wallin et al (1976) have shown that it is not the sympathetic nervous system that is at fault but the 1A afferents. These become hypersensitive to noradrenaline and are responsible for the continuous discharges that are seen in causalgic states. By recording from a sympathetic 
fascicle in a patient with spontaneous causalgic pain, they were able to show that transcutaneous electrical nerve stimulation (TENS) completely relieved the painful symptoms but had no effect on the sympathetic discharge. Moreover, in a patient with a partial femoral nerve lesion, the application of a cuff above systolic pressure-blocking the $\mathrm{C}$ fibres but retaining conduction in 1A fibres-completely abolished the pain (Ochoa and Torebjork, 1981).

Wall and Devor (1981) showed that within a week of division of the sciatic nerve of a rat, marked physical and chemical changes occurred in the dorsal horn and in the dorsal root ganglia. There is thus ample evidence that even minor damage to peripheral nerves produces profound peripheral and central effects.

One of the more bizarre results of these strange conditions is the development in a few patients of abnormal movements, for example Nathan (1978) described the onset of co-ordinated spontaneous movements in the toes following a number of root and central nervous lesions.

\section{Management}

Wall and Sweet (1969) were the first to report that electrical stimulation could relieve pain in humans. Wall and Gutnik (1974) showed that this worked experimentally both by reducing or silencing the spontaneous discharges on the neuroma and by diminishing the central activity in afferent fibres. Transcutaneous electrical nerve stimulation (TENS) has now become a routine part of the management of painful nerve disorders. It is logical to use TENS in patients who suffer predominantly from paraesthesiae and hyperaesthesiae.

In those patients in whom TENS produces a significant relief of pain, a stimulator is provided for home use. It is essential that the patient wears the stimulator for many hours a day for weeks on end. The effect is cumulative and the best results are obtained by prolonged use. Our own physiotherapists are highly skilled in the application of this treatment. They will experiment with different positions of the electrodes and different settings of pulse width, repetition rate and frequency over a period of 1 to 2 weeks (Frampton, 1982). The majority of patients prefer a high rate of stimulation in the $60-100 \mathrm{~Hz}$ range. There is some evidence to suggest that the effect of continuous high frequency electrical stimulation is mediated by endorphin release centrally, whereas brief, painful low frequency impulses (which a few patients prefer) stimulate other central inhibitory systems (Melzack and Wall, 1983). Whatever the rationale, there is no doubt that properly applied TENS is a most valuable form of treatment. We do not allow our patients to return the stimulator until they have been virtually painfree for a whole year.
In those patients where the predominant symptom is hyperpathia (allodynia) the treatment of choice will be a sympathetic block. Barnes (1954) pointed out that surgery in the form of neurolysis or nerve resection was not successful; sympathectomy was the only cure. This was more successful in the lower limb than in the upper limb. He reported 22 patients in whom sympathectomy had been carried out for causalgia and showed that in 15 there was dramatic long-lasting success. It now seems that the sympathetic nervous system itself is not at fault, but that the IA afferent fibres are hypersenstive to the normal sympathetic drive. It is logical, therefore, to block the sympathetic nervous system by one means or another, so as to reduce the hypersensitivity of the peripheral afferents. Classically this is effected by stellate ganglion block which, if only temporarily successful, can be followed by a definitive sympathectomy. However, many authors have pointed out that the sympathetic nervous system has an amazing capacity to regenerate and that the long-term results have been disappointing. It is because of this that the technique of guanethidine block (Hannington-Kiff, 1974) has become popular, as sympathetic blocks with guanethidine are not only longer lasting but are easier to carry out. Guanethidine blocks can be given routinely by the house officers and in our hands have been entirely free from side effects. The guanethidine displaces noradrenaline from the peripheral receptors and produces a total sympathetic block in the whole arm distal to the cuff.

We have been giving sympathetic blocks for painful nerve conditions now for 8 years. We now know that a minimum of three blocks are necessary and, if there is even a slight response to treatment, it is worth continuing with serial blocks as the effect is cumulative. Some of our patients have had as many as 12 or 20 blocks, and in three instances the number has exceeded 30 with long-lasting success. All these pain-relieving measures are a part of an intensive rehabilitation programme. All our patients are admitted to a rehabilitation ward. Here they take part in an intensive programme of exercises, games, occupational therapy, and desensitisation of the painful part. Not only is it necessary to regain movement in stiff joints and build up power in weak muscles, but normal movement patterns need to be restored as lack of input from the periphery leads to perpetuation of central firing.

Our patients are admitted for a minimum of 2 weeks during which time they are assessed by all the therapists in our team, nurse, physiotherapist, occupational therapist, social worker, clinical psychologist when necessary, and the resettlement officer if work is a problem. It is also important to provide long-term follow up. Many of these patients can lose their pain for weeks or months, only for it to creep back 
gradually, particularly in the cold weather. We have a number of patients who come back routinely every year or 18 months for a top-up treatment with serial blocks.

Some of our patients have been treated by a combination of TENS, guanethidine blocks and an intensive rehabilitation programme. This is logical as there are many reasons why damaged peripheral nerves cause pain. Occasionally serial nerve blocks with local anaesthetic can be helpful, but on the whole this is a disappointing treatment for the pain seems to return very quickly after the anaesthetic has worn off. Indeed in a few patients the pain has become worse for some days afterwards. It is logical, however, to think of ways in which one could, as it were, put the nerve to sleep for a prolonged period without producing permanent damage. This would stop ectopic firing, and abnormal discharges from developing and reaching the central nervous system. The nerve would thus settle down and more normal patterns would be restored in the central connections. There is some hope that agents that selectively block myelin and do not interfere with the function of the axis cylinder may become available. At the moment their use is strictly confined to the animal laboratory. In a few centres electrical implants have been inserted directly around peripheral nerves and some good results reported (Campbell and Long, 1976). Most surgeons have, however, abandoned these procedures as considerable problems arose including scarring, infection and gradual loss of efficacy.

In desperate cases when the patient is almost suicidal with pain, or when the family beg that something radical is done because of the patient's change of personality and the deleterious effects on family life, it may be necessary to consider drastic measures. It is now generally agreed by neurosurgeons that destructive procedures should not be undertaken for intractable pain of benign origin, that is, in patients with a normal life expectancy. The pain invariably returns, often worse than before, despite destruction of what are believed to be the major afferent tracks. We know that there are at least seven tracks that carry nociceptive information and there is marked redundancy in the central nervous system to a degree undreamt of some years ago. Thus, rhizotomy, cordotomy, tractotomy, are all universally condemned. However, Nashold et al. (1976) and Nashold and Ostdahl (1979) have shown that destruction of the dorsal root entry zone, the site of abnormal spontaneous firing after avulsion lesions of the brachial plexus, can produce prolonged relief of pain. This seems logical as one is tackling the source of the pain by destroying cells that are firing abnormally. In some patients pain returns after months or years, but a number of patients have been undeniably helped and several saved from probable suicide. The selection of such patients for dorsal root entry zone destructive procedures must be very careful and should not be contemplated until every other form of treatment has been tried. Although Mazaars (1976) is enthusiastic about thalamic stimulation, Gybels (1984) and others in this field find that it is seldom effective in deafferentation pain.

\section{Drug treatment}

Drug treatment is singularly disappointing and analgesics and anti-inflammatory drugs are of no value. If the patient has severe shooting pains, suggesting that the predominant problem is paroxysmal central discharges as in trigeminal neuralgia, carbamazepine should be tried as it is occasionally helpful. This is particularly valuable in the deafferentation syndrome such as after avulsion lesions of the branchial plexus and chronic intractable sciatica after multiple surgery. Periodically, reports appear of the dramatic effect in Sudeck's atrophy and the shoulder-hand syndrome of large doses of a corticosteroid. These do not stand up to critical analysis and most workers have abandoned their use. The demonstration that beta-blockers, in particular propanolol could prevent the autotomy in rats after nerve section led to its clinical trial by Scadding (1984). The results were disappointing and, although there have been anecdotal reports of its value in phantom pain after amputation, we have not been able to demonstrate any use for this drug in causalgia. In our experiences and that of most others, acupuncture is of no value in severe intractable pain.

\section{Role of surgery to the peripheral nerve}

In contrast to the experience of those in the 19th century, peripheral nerve surgery has proved to be extremely disappointing. Seeing a patient in the clinic, who has divided his median nerve at the wrist, and who has had a primary suture, only to be followed by the development of a very painful neuroma, with severe hyperpathia and inability to use the hand, it would seem logical to resect the neuroma and carry out a definitive careful suture with or without nerve grafting under the microscope. All too often, such attempts, logical as they may seem, lead to recurrence of severe pain some weeks or months later (Nordenbos and Wall, 1981). Sunderland (1978), in the recent edition of his book entitled Peripheral Nerve Injuries, points out that reaction is rarely successful, the lesion is likely to be in continuity, section therefore may do damage and the cause of the pain is central. Possibly results are better in digital nerve lesions. Tupper and Booth (1976) report $32 \%$ of excellent results after one resection in 172 patients, and $32 \%$ excellent after two resections, with decreasing success after a second operation. Capping the neuroma with silicon rubber caps was 
unhelpful. Snyder (1961) reported 150 surgical procedures for painful neuromas including putting the nerve into bone or muscle, cutting the nerve, crushing it, sheathing it with millipore, gold foil, tantalum, and even cerebrospinal fluid, destroying it with chemical fixatives, sclerosis, coagulation and freezing. One thing seems quite clear-continuity should be established where possible. Leaving a bare end of nerve to act as a spontaneous generator of nerve impulses is to be deplored.

\section{Results}

The authors reviewed 86 patients with severe pain from peripheral nerve damage (Withrington and Wynn Parry, 1984). The mean time pain was suffered before treatment was 3.4 years. In 49 of the $69(71 \%)$ patients who had surgical lesions, substantial relief was obtained, either by electrical stimulation or guanethedine blocks, or a combination of both (Table 1). In these patients, no less than 71 operations were carried out, before referral to the Pain Service, and in only one was the operation successful (Table 2).

TABLE 1. Painful peripheral nerve lesions (Royal National Orthopaedic Hospital 1979-1983)

\begin{tabular}{lrcc}
\hline & $n$ & Helped & $\begin{array}{c}\text { Not } \\
\text { helped }\end{array}$ \\
\hline Median nerve & 18 & 12 & 6 \\
Ulnar nerve at elbow & 12 & 7 & 5 \\
Ulnar nerve at wrist & 2 & 2 & 0 \\
Digital nerve & 22 & 16 & 6 \\
Superficial radial nerve & 3 & 3 & 0 \\
Scar & 6 & 4 & 2 \\
Others & 6 & 5 & 1 \\
Total & & 49 & 20 \\
\hline
\end{tabular}

TENS helped 30 out of 59 patients treated. Guanethidine helped 29 out of 58 patients treated. Eleven patients were helped by both. Fifty patients had 71 operations for pain, one was successful.

Table 1 shows the breakdown of the causes of pain, and those in whom it was possible for us to help. We have not graded the results other than to record substantial relief or no relief. The following maxims have been adopted by our surgical team (R. Birch) in conditions of severe pain:

(1) Restore continuity if possible. If not, make a clean cut of the nerve and allow retraction.

(2) Only the highest quality technique is allowed.

(3) Never carry out internal neurolysis.

(4) Respect the anatomy of the nerve, for example, the palmar cutaneous branch of the median nerve can be but should never be damaged in operation for carpal tunnel.

(5) Only one attempt to relieve pain by surgery to the peripheral nerve is allowed.

(6) Long-term follow-up is essential as these patients relapse with time and intensive rehabilitation is an absolutely essential part of the treatment.

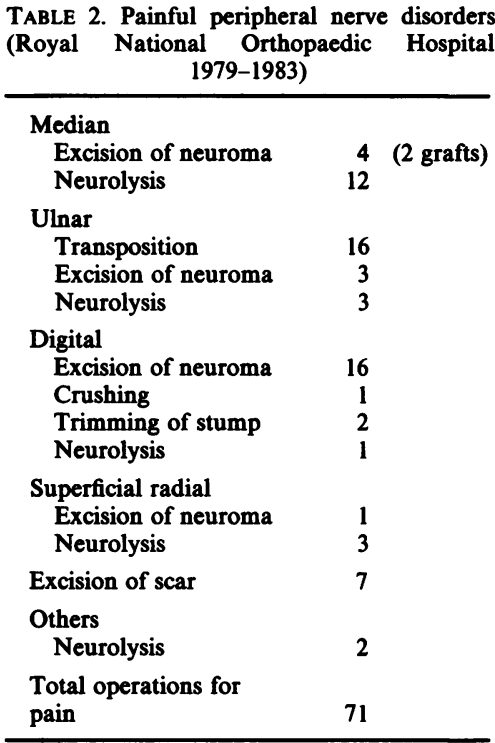

Table 3 shows the results of treatment in the 'nonsurgical' group which contained 17 of the total of 86 patients reviewed. We were able to relieve pain substantially in $50 \%$ of these patients.

TABLE 3. 'Non-surgical' group

\begin{tabular}{lcc}
\hline & Helped & Not helped \\
\hline Phantom pain & 2 & 5 \\
Post-herpetic neuralgia & 2 & 1 \\
Sudeck's atrophy & 5 & 2 \\
\hline
\end{tabular}

\section{Pain after amputation}

There are two major causes of pain after amputation. Stump pain and phantom limb pain. Pain in the stump can arise from neuromata, or scarring and tethering of nerves to bone. With elective amputation carried out by surgeons specially trained in this field, stump pain should be rare. The nerve should be cut cleanly and allowed to retract and any adherence of the nerve to soft tissue or bone assidiously avoided. Occasionally hyperpathic and sensitive areas are found along incision lines, and refashioning of the stump may be worth considering. The vast majority of pain arising from the stump is due to poor surgery, or unsatisfactory stumps in traumatic lesions.

Whilst the sensation of a phantom is almost invariable, phantom pain is rare, somewhere between 
5-10\% of amputations. A recent report (Jensen et al., 1983) suggests that phantom pain is felt in $60 \%$ of patients immediately after amputation but lessens by 6 months and thereafter falls progressively. There is no doubt that phantom pain is much more likely to develop if there has been pain before amputation, and assiduous efforts must be made to abolish the pain before amputation. There are a vast number of treatments described for phantom pain indicating that no one is universally successful. We have had encouraging experiences with transcutaneous electrical nerve stimulation (TENS), given over a prolonged period for many hours a day, as described for causalgia. Various placements of the electrodes must be tried and physiotherapists must be prepared to experiment over many days or weeks, before abandoning this treatment as unsuccessful.

Phantom pain is a particular example of deafferentation pain. Cells denied their normal afferent input become spontaneously active and abnormal circuits are set up which may spread centrally up to the thalamus (Anderson et al., 1971). Pain after avulsion lesions of the brachial plexus is an extreme example of deafferentation pain, not only much more common but much more severe, no doubt due to the vastly increased central damage occurring in a traction lesion. In both situations, the pain is characteristically continuous, of a crushing, burning nature, often feeling as if the hand or foot is held in a vice, with periodic paroxysms of pain which may be felt several times an hour, or several times a day. The pain may take some weeks to develop although there is an immediate onset in a significant proportion. Wynn Parry (1980) has shown that the incidence of avulsion pain in total lesions of the brachial plexus approaches $90 \%$ and the natural history of such pain is disappointing in that a high proportion of patients suffer chronic pain. Of proven value are the careful use of TENS, the regular use of prosthesis in amputees and an intensive rehabilitation programme with return to work or meaningful and absorbing hobbies. Occasionally drugs such as carbamazepine are of value when paroxysmal pain predominates. The single most valuable means of combating chronic pain is mental distraction, for the patient is mobilising his own central inhibitory pathways to gate off the abnormal firing, in order to concentrate on meaningful activities. It is thus vital that such patients return to work whenever possible. To this end we have devised special splints for the flail arm which can significantly improve function (Wynn Parry, 1981). In our rehabilitation unit, we have two resettlement officers who are an integral part of the rehabilitation team. They have had wide experience of industry, both on the shop floor and in a managerial capacity and can talk to employers in a realistic way. Their role is to establish as early as possible the nature of the patient's job and to make 3 contact with the employer. Subsequently, they willo

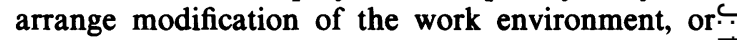
suitable alternative work in the same firm, or failing this, retraining courses for more suitable work. Their success is shown by the fact that $85 \%$ of our patients with complete brachial plexus lesions have returned $\overline{\bar{n}}$ to work.

\section{Conclusions}

A lot has been learned in the last 10 years about the $\vec{\circ}$ causes of these curious painful reactions to nervedamage. We now have some valuable methods of treatment which must be integrated into a compre- -8 hensive rehabilitation programme, with return to 3 . work or meaningful hobbies as the goal. We haveo learnt that, however logical it may seem, repeated attempts to cure the pain by surgery are doomed to $\vec{\circ}$ failure. While we cannot predict who will developo painful sequelae to nerve damage, whether it be toc major nerves as in causalgia, or minor nerves as in을 the algodystrophies, we know that at the slightest signof the development of this condition, treatment must? be prosecuted intensively and immediately. In those patients in whom there is a past history of such 3 reactions and in whom surgery is essential, perhaps? one should administer prophylactic guanethidi $8 e_{-}^{-}$ blocks or provide a transcutaneous nerve stimulat $\stackrel{\varnothing}{\varnothing}$

The best results will be obtained by close liasont between all members of the rehabilitation team, be they surgeon, physician, remedial therapist, psycho-命 logist or resettlement officer. Furthermore, a close liaison is vital between the clinical team and the basico scientists. The clinical team demonstrates to the $\frac{\Phi}{\circ}$ scientist the nature of the clinical problems and the $\overrightarrow{\vec{A}}$ scientist updates the clinicians in experimental ad-응 vances, identifying the causes of nerve damage and $\vec{\supset}$ the rationale for possible ways of modifying its response. This is an exciting and challenging field with the very real possibility of major advances in the 3 forseeable future.

\section{References}

ANDERSON, L.S., BLACK, R.G., ABRAHAM, V. \& WARD, A.A. (1971) Neuronal hyperactivity in experimental trigennual deafferenta윽 tion. Journal of Neurosurgery, 35, 444.

BARNES, R. (1954) Causalgia. A review of 48 cases in 'Peripherafo nerve injuries'. Report of the Medical Research Council, 156.

CAMPBell, J.N. \& LONG, D.M. (1976) Peripheral nerve stimulation N in the treatment of intractable pain. Journal of Neurosurgery, 45 ,

692.
FRAMPTON, V. (1982) Pain control with the aid of transcutaneous nerve stimulation. Physiotherapy, 68, 77.

Gybels, J. (1984) Communication to Symposium on Neurologica攵 Aspects of Chronic Pain-in honour of P. Nathan's 70th Birthdaye London.

HANINGTON-KIFF, J. (1974) Intravenous regional sympathetic blocks with guanethidine. Lancet, i, 1019.

INBAL, R., DeVoR, M., TUCHENDleR, O. \& Lieblik, K. (1980) 
Anatomy following nerve injury. Genetic factors in the development of chronic pain. Pain, 9, 327.

Jensen, T.S., Krebs, B., Nielsen, J. \& Rasmussen, P. (1983) Phantom limb, phantom pain and stump pain in amputees during the first 6 months following limb amputation. Pain, 17, 243.

Livingston, W.K. (1943) Pain Mechanisms. A Physiological Interpretation of Causalgia and its Related States. MacMillan Co., New York.

LoH, L. \& Nathan, P.W. (1978) Painful peripheral states and sympathetic blocks. Journal of Neurology, Neurosurgery and Psychiatry, 41, 664.

MAZAARS, G.J. (1976) Contribution of thalamic stimulation to the physiopathology of pain. In: Advances in Pain Research and Therapy. Vol. I. (Eds. J. J. Bonica and D. Albe Fessard), p. 483. New York, Raven Press.

Melzack, R. \& Wall, P.D. (1983) The Challenge of Pain. Penguin Books, Harmondsworth, Middlesex.

MitCHELL, J.K. (Ed.) (1895) Remote Consequences of Injuries of Nerves and their Treatment J. B. Lippincott, Philadelphia.

NASHOLD, B.S., URBaN, B. \& ZoRAB, D.S. (1976) Phantom pain relief by Focal destruction of the Substantia gelatinosa of Rolands. In: Advances in Pain Research and Therapy (Ed. J. J. Bonica and A. Fessand). Vol. 1. Raven Press, New York.

NASHOLD, B.S. \& OSTDAHL, R.H. (1979) Dorsal root entry zone lesions for pain relief. Journal of Neurosurgery, 57, 59.

Nathan, P.W. (1978) Painful legs and moving toes. Evidence on the site of the lesion. Journal of Neurology, Neurosurgery and Psychiatry, 41, 934.

NORDENBOS, W. \& WALL, P.D. (1981) Implications of the failure of nerve resection and graft to cure chronic pain produced by nerve lesions. Journal of Neurology, Neurosurgery and Psychiatry, 44, 1068.

OCHOA, J. \& TOREBJORK, H.W. (1981) Paraesthesiae from ectopic impulse generation in human sensory nerves. Brain, 103, 835-53.

SCADDING, J.W. (1984) Ectopic impulse generation in damaged peripheral axons in abnormal nerves and muscles as impulse generators. In Abnormal Nerves and Muscles as Impulse Genera- tors. (Eds. J. Ochoa and W. Culp), Oxford University Press, Oxford.

SCADDING, J.W., WaLl, P.D., WYNn PARRY, C.B. \& BROOKs, D.M. (1982) Clinical trial of propranolol in post-traumatic neuralgia. Pain, 14, 283.

SNYDER, C. (1961) The Surgical Handling of Tissue. Proceedings 7th Annual Convention, American Association Equine Practice. Texas.

SUDEK, P. (1900)Uber die akute eutzu nahiche knockens thopi. Archiv für klinische chirurgie, $62,147$.

SUNDERLAND, S. (1978) Nerves and nerve injuries. Churchill Livingstone. Edinburgh, London and New York.

TUPPER, J.W. \& BOOTH, D.M. (1976) Treatment of painful neuromas of sensory nerves in the hand. A comparison of traditional and newer methods. Journal of Hand Surgery, 1, 144.

Wall, P.D. \& GUTNIK, M. (1974) Properties of afferent nerve impulses originating from a neuroma. Nature, 248, 740.

WALL, P.D. \& DEVOR, M. (1981) The effect of peripheral nerve injury on dorsal root potentials and on transmission of afferent signals into the spinal cord. Brain Research, 209, 95.

WALL, P.D. \& SWEET, W.H. (1967) Temporary abolition of pain in man. Science, 155, 108.

Wallin, G., TOREBJóRK, E. \& Hallin, R. (1976) Preliminary observations on the pathophysiology of hyperalgesia in the causalgic pain syndrome. In: Sensory Function of The Skin in Primates. (Ed. Y. Zotterman), p. 489. Pergamon Press, Oxford.

WEIR-MITCHELL, S. (1872) Injuries of nerves and their consequences. (Reprinted 1965), Dover Publications, New York.

WhiTE, J.C., HeroY, W.W., Goodman, E.N. (1948) Causalgia following gunshot injuries of nerves. Role of emotional stimuli and surgical care through interruption of diencephatic efferent discharge by sympathectomy. Annals of Surgery, 121, 161.

WITHR INGTON, R.H. \& WYNN PARRY, C.B. (1984) Management of painful peripheral nerve disorder. Journal of Hand Surgery, 9, 24.

WYNN PARRY, C.B. (1980) Pain in avulsion lesions of the brachial plexus. Pain, 9, 41.

WYNN PARRY, C.B. (1981) Rehabilitation of the Hand. 4th edn. Butterworth, London. 